\title{
Collusion and Reciprocity in Infinitely Repeated Games ${ }^{\dagger}$
}

\author{
Luís Santos-Pinto \\ Universidade Nova de Lisboa, Departamento de Economia \\ Campus de Campolide, PT-1099-032, Lisboa, Portugal \\ Email address: lspinto@fe.unl.pt
}

April 18, 2007

\begin{abstract}
This paper extends the standard industrial organization models of repeated interaction between firms by incorporating preferences for reciprocity. A reciprocal firm responds to unkind behavior of rivals with unkind actions (destructive reciprocity), while at the same time, it responds to kind behavior of rivals with kind actions (constructive reciprocity). The main finding of the paper is that, for plausible perceptions of fairness, preferences for reciprocity facilitate collusion in infinitely repeated market games, that is, the critical discount rate at wish collusion can be sustained tends to be lower when firms have preferences for reciprocity than when firms are selfish. The paper also finds that the best collusive outcome that can be sustained in the infinitely repeated Cournot game with reciprocal firms is worse for consumers than the best collusive outcome that can be sustained in the infinitely repeated Cournot game with selfish firms.
\end{abstract}

JEL Classification Numbers: D43, D63, L13, L21.

Keywords: Reciprocity; Fairness; Collusion; Repeated Games.

${ }^{\dagger}$ I am thankful to Rosa Branca Esteves for having asked the right question. I am also thankful to Guilherme Carmona for insightful comments. I gratefully acknowledge financial support from an INOVA grant. 


\section{Introduction}

The factors that facilitate collusion are now well know in industrial organization: concentration, barriers to entry, cross-ownership, symmetry, multi-market contracts, among others, all have been show to make collusion more likely. ${ }^{1}$

This paper makes an additional contribution to this literature in that it identifies one more factor that eases collusion: preferences for reciprocity by the part of firms. A firm whose preferences reflect reciprocity is willing to sacrifice some of its own monetary profits to reduce the monetary profits of its rivals in response to unkind behavior, while at the same time, is willing to sacrifice some of its own monetary profits to increase the monetary profits of its rivals in response to kind behavior.

The paper finds that, under plausible perceptions of fairness, firms preferences for reciprocity facilitate collusion in infinitely repeated market games. The result is valid for both infinitely repeated Cournot and Bertrand market games. The intuition for the result in the infinitely repeated Cournot game is as follows.

If firms have preferences for reciprocity, the one-shot Nash outcome used in grim trigger strategies is a destructive reciprocity state, that is, a state in which firms think that their rivals are mean to them. Thus, reversion to playing the one-shot Nash forever is worse for reciprocal firms than for selfish ones. Additionally, for plausible specifications of perceptions of fairness, the collusive outcome is a constructive reciprocity state, that is, a state in which firms think that their rivals treat them kindly. These two effects imply that the critical discount rate at wish collusion can be sustained tends to be lower when firms have preferences for reciprocity than when firms are selfish.

In the infinitely repeated Bertrand game preferences for reciprocity do not alter the payoff of the punishment outcome (in the grim trigger strategy price is set equal to marginal cost by both firms and so monetary profits are zero) nor the payoff of the one period deviation (the firm that deviates by undercutting the price of the rival forces the monetary profits of the rival to be equal to zero). However, preferences for reciprocity may raise the payoff of collusion when firms' perceptions of what is the fair market price are strictly below the monopoly price.

This paper is related to a recent strand of literature in economics that studies the consequences of relaxing the assumption of individual greed. ${ }^{2}$ This literature is motivated by experimental evidence that shows that individuals are not only motivated by material self-interest, but also care about the intentions of others. ${ }^{3}$

\footnotetext{
${ }^{1}$ For an excellent review of the findings of the economic literature on collusion see Feuerstein (2005).

${ }^{2}$ Sobel (2005) argues that models of interdependent preferences such as reciprocity can provide clearer and more intuitive explanations of interesting economic phenomena.

${ }^{3}$ It is more traditonal to view trust and reciprocity as the result of optimizing actions of selfish agents in models of reputation and repeated interaction. One recent example is Abdulkadiroğlu and Bagwell (2005). They consider a repeated trust game with private information and use this framework to explain the provision of favors among individuals in on-going relationships.
} 
Preferences for reciprocity were first modeled in the economics literature by Rabin (1993) in the context of static games using the theory of psychological game by Geanakoplos et al. (1989). In Rabin's model the weight a firm places on a rival's monetary profits depends on the interpretation of that rival's intentions which are evaluated using beliefs (and beliefs about beliefs) over strategy choices. This approach provides a model of preferences for reciprocity since a firm places a positive weight on a rivals' profit when the firm thinks that the behavior of the rival is nice and negative if it thinks that the behavior is nasty.

Segal and Sobel (1999) provide an axiomatic foundation for non-selfish preferences that can reflect preferences for reciprocity, inequity aversion, altruism as well spitefulness. They assume that in addition to conventional preferences over outcomes, players in a strategic environment also have preferences over strategy profiles. I apply Segal and Sobel's (2005) approach to study the impact of preferences for reciprocity on collusion since using psychological games would complicate the analysis substantially without providing additional insights into the problem.

The impact of preferences for reciprocity on strategic interactions between firms has not received much attention. The only exceptions are Bolton and Ockenfels (2000) and Santos-Pinto (2006). Bolton and Ockenfels (2000) find that inequity aversion has no impact on Cournot and Bertrand competition. Santos-Pinto (2006) shows that if reciprocal firms compete à la Cournot, then they are able to sustain collusive outcomes under a constructive reciprocity equilibrium. By contrast, Stackelberg warfare outcomes may emerge under a destructive reciprocity equilibrium.

The rest of the paper proceeds as follows. Section 2 sets-up the infinitely repeated Cournot model with reciprocal firms. Section 3 specializes the model. Section 4 contains the main results. Section 5 presents additional findings. Section 6 studies the impact of preferences for reciprocity on collusion in the context of the infinitely repeated Bertrand game. Section 7 concludes the paper. The Appendix contains the proofs of all propositions.

\section{Set-up}

Consider an infinitely repeated Cournot game, where firms $i=1,2, \ldots, n$, repeatedly play the Cournot game over an infinite horizon $t=0,1,2, \ldots$ In each period firm $i$ chooses output and its payoff in that period is given by

$$
u_{i}\left(q_{i}, Q_{-i}\right)=\pi_{i}\left(q_{i}, Q_{-i}\right)+w_{i}\left(Q_{-i}, Q_{-i}^{f}\right) \sum_{j \neq i} \pi_{j}\left(q_{i}, Q_{-i}\right),
$$

where $\pi_{i}\left(q_{i}, Q_{-i}\right)$ are monetary profits and $w_{i}\left(Q_{-i}, Q_{-i}^{f}\right) \sum_{j \neq i} \pi_{j}\left(q_{i}, Q_{-i}\right)$ is the payoff from preferences for reciprocity. ${ }^{4}$ As usual, firm $i$ 's monetary profits depend on firm $i$ 's output, $q_{i}$, and on the aggregate output of its rivals, $Q_{-i}$, in

\footnotetext{
${ }^{4}$ Segal and Sobel (1999) provide axiomatic foundations for this type of preferences.
} 
that

$$
\pi_{i}\left(q_{i}, Q_{-i}\right)=R_{i}\left(q_{i}, Q_{-i}\right)-C_{i}\left(q_{i}\right)
$$

where $R_{i}\left(q_{i}, Q_{-i}\right)=P(Q) q_{i}$ is the revenue of the firm. Price is determined according to the inverse demand function $P(Q)$, where $Q=\sum q_{i}, P(Q)$ is strictly positive on some bounded interval $(0, \bar{Q})$ with $P(Q)=0$ for $Q \geq \bar{Q}$ and $P(Q)$ is strictly decreasing in the interval for which $P(Q)>0$. Firms have costs of production given by $C_{i}\left(q_{i}\right)$ which are increasing in $q_{i}$.

The term $w_{i}\left(Q_{-i}, Q_{-i}^{f}\right) \sum_{j \neq i} \pi_{j}\left(q_{i}, Q_{-i}\right)$ represents preferences for reciprocity where $w_{i}\left(Q_{-i}, Q_{-i}^{F}\right)$ is the weight that firm $i$ places on its rivals' monetary profits $\sum_{j \neq i} \pi_{j}\left(q_{i}, Q_{-i}\right)$. The weight firm $i$ places on its rivals' monetary profits depends on firm $i$ 's perception of the fair output of its rivals, $Q_{-i}^{f}$, and on the output of firm $i$ 's rivals such that

$$
w_{i}\left(Q_{-i}, Q_{-i}^{f}\right)\left\{\begin{array}{l}
>0 \text { if } Q_{-i}<Q_{-i}^{f} \\
=0 \text { if } Q_{-i}=Q_{-i}^{f} \\
<0 \text { otherwise }
\end{array}\right.
$$

that is, firm $i$ places a positive weight on its rivals' monetary profits when the rivals produce less than $Q_{-i}^{f}$, firm $i$ places no weight on its rivals' monetary profits when the rivals produce $Q_{-i}^{f}$, and firm $i$ places a negative weight on its rivals' monetary profits when the rivals produce more than $Q_{-i}^{f}$.

These conditions capture the fact that a firm with reciprocal preferences cares about the intentions of its rivals. The first condition expresses positive reciprocity. If firm $i$ expects the aggregate output of its rivals to fall short of its own perception of the fair aggregate output of its rivals, then firm $i$ is willing to sacrifice some of its monetary profits to increase the rivals' monetary profits. The third condition expresses negative reciprocity. When firm $i$ expects its rivals to produce more than firm $i$ 's perception of the fair aggregate output of its rivals, then firm $i$ is willing to sacrifice some of its profit to reduce the rivals' profit. $^{5}$

I assume throughout that firms' preferences for reciprocity as well as firms' perceptions of the fair output level of its rivals are common knowledge. ${ }^{6}$ Lemma 2 in Santos-Pinto (2006) provides conditions under which there is a unique equilibrium of the stage game with reciprocal firms when $n=2$.

Firms discount the future at rate $\delta \in(0,1)$. The repeated game payoff is

\footnotetext{
${ }^{5}$ Weighting functions that satisfy condition (1) arise naturally. For example, $w_{i}\left(Q_{-i}, Q_{-i}^{f}\right)=\alpha\left(Q_{-i}^{f}-Q_{-i}\right), w_{i}\left(Q_{-i}, Q_{-i}^{f}\right)=\alpha\left(Q_{-i}^{f}-Q_{-i}\right)^{3}$, or $w_{i}\left(Q_{-i}, Q_{-i}^{f}\right)=$ $\alpha\left(Q_{-i}^{f} / Q_{-i}-1\right)$, with $\alpha>0$.

${ }^{6}$ This means that firms' perceptions of fairness are exogenous to the model. This assumption may be unreasonable in many settings. Studying situations where firms' perceptions of fairness are endogenous variables is an interesting avenue for research.
} 
given by

$$
U_{i}=\sum_{t=0}^{\infty} u_{i}\left(q_{i}, Q_{-i}\right) \delta^{t}
$$

The incentive compatibility condition for a selfish firm $i$ to sustain collusion using a grim trigger strategy is that the payoff from collusion, $\pi_{i}^{c s}\left(q_{i}^{c s}, Q_{-i}^{c s}\right) /(1-$ $\delta)$, must be no less than the payoff from defection which consists of the one period gain from deviating $\pi_{i}^{d s}\left(B R_{i}^{s}\left(Q_{-i}^{c s}\right), Q_{-i}^{c s}\right)$ plus the discounted payoff of inducing Nash reversion forever $\delta \pi_{i}^{n s}\left(q_{i}^{n s}, Q_{-i}^{n s}\right) /(1-\delta)$. That is,

$$
\pi_{i}^{d s}\left(B R_{i}^{s}\left(Q_{-i}^{c s}\right), Q_{-i}^{c s}\right)+\frac{\delta}{1-\delta} \pi_{i}^{n s}\left(q_{i}^{n s}, Q_{-i}^{n s}\right) \leq \frac{1}{1-\delta} \pi_{i}^{c s}\left(q_{i}^{c s}, Q_{-i}^{c s}\right)
$$

Solving for $\delta$ we obtain

$$
\delta_{q^{c s}}^{s}=\frac{\pi_{i}^{d s}-\pi_{i}^{c s}}{\pi_{i}^{d s}-\pi_{i}^{n s}} \leq \delta
$$

When firms are selfish it follows that collusion can be sustained if firms are patient enough such that $\delta_{q^{c s}}^{s} \leq \delta$ where $\delta_{q^{c s}}^{s}$ is the critical discount factor above which the selfish collusive outcome can be sustained by selfish firms.

The same reasoning applies when firms have reciprocal preferences with the difference that the payoffs depend on quantities produced and firms' perceptions of fairness. Thus, the incentive compatibility condition for a reciprocal firm $i$ to sustain the selfish collusive outcome using a grim trigger strategy is now

$$
u_{i}^{d r}\left(B R_{i}^{r}\left(Q_{-i}^{c s}\right), Q_{-i}^{c s}\right)+\frac{\delta}{1-\delta} u_{i}^{n r}\left(q_{i}^{n r}, Q_{-i}^{n r}\right) \leq \frac{1}{1-\delta} u_{i}^{c r}\left(q_{i}^{c s}, Q_{-i}^{c s}\right)
$$

Solving for $\delta$ we obtain

$$
\delta_{q^{c s}}^{r}=\frac{u_{i}^{d r}-u_{i}^{c r}}{u_{i}^{d r}-u_{i}^{n r}} \leq \delta
$$

When firms have reciprocal preferences it follows that the selfish collusive outcome can be sustained if firms are patient enough such that $\delta_{q^{c s}}^{r} \leq \delta$ where $\delta_{q^{c s}}^{r}$ is the critical discount factor above which the selfish collusive outcome can be sustained by reciprocal firms.

I will use (2) and (3) to characterize the impact that preferences for reciprocity have on collusion in a dynamic Cournot oligopoly. To perform this analysis I compare the critical discount factor above which the selfish collusive outcome can be sustained in the game with selfish firms to that in the game with reciprocal firms. I assume that these two games are identical in all respects (market demand, costs, and number of firms) with the exception of firms' preferences. I say that preferences for reciprocity facilitate collusion when the selfish collusive outcome can be sustained at a lower critical discount factor in the game with reciprocal firms than in the game with selfish firms. If the opposite happens I say that preferences for reciprocity make collusion harder. 


\section{The Specialized Model}

To explain how preferences for reciprocity influence collusion I need to specialize the model. To that purpose I consider a symmetric Cournot duopoly where the two firms in the market are labelled firm 1 and firm 2. The firms have a common constant marginal cost of production, which, without loss of generality, is taken to be zero. Market demand is given by the inverse demand function $p=(a-b Q)^{x}$, where $Q=q_{1}+q_{2}, q_{i}$ denotes firm $i$ 's output, and $a, b, x>0$ are demand parameters. Price equals zero if total output exceeds $a / b$. This demand function is convex for $x>1$, linear for $x=1$, and concave for $0<x<1$. $^{7}$

Each firm cares about the intentions of its rival through the function

$$
w_{i}\left(q_{j}, q^{f}\right)=\alpha\left(\frac{q^{f}}{q_{j}}-1\right), i \neq j=1,2,
$$

with $\alpha>0$ and $q^{f}=\beta \frac{1}{2+x} \frac{a}{b}$, where $\beta \in[0,1] .{ }^{8}$ That is, if the rival produces less than $q^{f}$ then firm $i$ feels positive reciprocity towards the rival and places a positive weight on the rival's monetary profits. However, if the rival produces more than $q^{f}$ then firm $i$ feels negative reciprocity towards the rival and places a negative weight on the rival's monetary profits. The parameter $\beta$ measures each firm's perception of what is the fair output of its rival. If $\beta$ is zero then a firm believes that it is fair for the rival to produce zero output, if $\beta$ is 1 then a firm thinks that it is fair for the rival to produce the Nash equilibrium quantity of the single period game with selfish firms, for intermediate values of $\beta$ a firm believes that it is fair for the rival to produce an output level greater than zero but smaller than $\frac{1}{2+x} \frac{a}{b}$.

Under these assumptions firm $i$ 's single period payoff, $u_{i}$, is given as follows:

$$
\begin{aligned}
u_{i}\left(q_{i}, q_{j}\right) & =(a-b Q)^{x} q_{i}+\alpha\left(\frac{\beta a}{b(2+x) q_{j}}-1\right)(a-b Q)^{x} q_{j} \\
& =\left(q_{i}+\frac{\alpha \beta a}{b(2+x)}-\alpha q_{j}\right)(a-b Q)^{x} .
\end{aligned}
$$

The partial derivative of $u_{i}$ with respect to $q_{i}$ is

$$
\begin{aligned}
\frac{\partial u_{i}}{\partial q_{i}} & =(a-b Q)^{x}-b x(a-b Q)^{x-1}\left(q_{i}+\frac{\alpha \beta a}{b(2+x)}-\alpha q_{j}\right) \\
& =(a-b Q)^{x-1}\left[a-b Q-b x\left(q_{i}+\frac{\alpha \beta a}{b(2+x)}-\alpha q_{j}\right)\right] .
\end{aligned}
$$

Solving $\partial u_{i} / \partial q_{i}=0$ for $q_{i}$ one obtains firm $i$ ' best reply

$$
B R_{i}\left(q_{j}\right)= \begin{cases}\frac{2+x-\alpha \beta x}{(2+x)(1+x)} \frac{a}{b}-\frac{1-\alpha x}{1+x} q_{j} & \text { if } 0 \leq q_{j} \leq \frac{2+x-\alpha \beta x}{(1-\alpha x)(2+x)} \frac{a}{b} \\ 0 & \text { if } \frac{2+x-\alpha \beta x}{(1-\alpha x)(2+x)} \frac{a}{b} \leq q_{j} .\end{cases}
$$

\footnotetext{
${ }^{7}$ This specification of demand follows Malueg (1992).

${ }^{8}$ This function captures the essence of preferences for reciprocity without making the problem too complicated.
} 
For $\alpha \in\left(0, \frac{1}{x}\right)$ the equilibrium of the single period Cournot game with reciprocal firms is unique and symmetric, that is, both firms choose the same output $q^{n r}$ which is the solution to $q^{n r}=B R_{i}\left(q^{n r}\right)$. Thus, the quantity produced by each firm in the equilibrium of single period game with reciprocal firms is given by $q^{n r}=\frac{2+x-\alpha \beta x}{(2+x)(2+x-\alpha x)} \frac{a}{b}$ and the payoff of each firm is

$$
u^{n r}=\frac{a^{1+x}}{b} x^{x}\left[\frac{(2+x)(1-\alpha)+2 \alpha \beta}{(2+x)(2+x-\alpha x)}\right]^{1+x} .
$$

It follows from (5) that $u^{n r}$ is decreasing with $\alpha$ when $\beta<1$, that is, if a reciprocal firm thinks that the fair output of its rival is less than $q^{n s}=\frac{1}{2+x} \frac{a}{b}$, then an increase in the importance of preferences for reciprocity reduces the payoff of the Nash equilibrium of the one-shot Cournot game. This shows that for $\beta<1$ the punishment imposed after cheating occurs becomes more severe as preferences for reciprocity become more important.

The aggregate monopoly (collusive) output of the game with selfish firms can be calculated from (4) by setting $\alpha=0$ and $q_{j}=0$. This yields a total monopoly output of $\frac{1}{1+x} \frac{a}{b}$, so each firm's equal share of the monopoly output is $q^{c s}=\frac{1}{1+x} \frac{a}{2 b}$. Thus, the payoff of a reciprocal firm from sustaining the collusive quantity of the game with selfish firms is given by

$$
u^{c r}\left(q^{c s}\right)=\frac{a^{1+x}}{2 b} x^{x} \frac{(2+x)(1-\alpha)+2 \alpha \beta(1+x)}{(2+x)(1+x)^{1+x}} .
$$

It follows from (6) that $u^{c r}\left(q^{c s}\right)$ is increasing with $\alpha$ when $\beta>\frac{2+x}{2(1+x)}$, that is, if a reciprocal firm thinks that the fair output of its rival is greater than $\frac{1}{1+x} \frac{a}{2 b}$, then an increase in $\alpha$ increases the payoff that reciprocal firms get when they sustain the collusive outcome of the game with selfish firms. Thus, for $\beta>\frac{2+x}{2(1+x)}$ the gains from cooperation increase as preferences for reciprocity become more important.

A reciprocal firm that deviates optimally from $q^{c s}$ would choose output $q^{d r}$ given by

$$
\begin{aligned}
q^{d r}\left(q^{c s}\right) & =B R_{i}\left(q^{c s}\right) \\
& =\frac{2+x-\alpha \beta x}{(2+x)(1+x)} \frac{a}{b}-\frac{1-\alpha x}{1+x} \frac{1}{1+x} \frac{a}{2 b} \\
& =\frac{(2+x)(1+2 x+\alpha x)-2 \alpha \beta x(1+x)}{(2+x)(1+x)^{2}} \frac{a}{2 b} .
\end{aligned}
$$

The single period payoff from the deviation is equal to

$$
\begin{aligned}
u^{d r}\left(q^{c s}\right) & =\pi\left(B R\left(q^{c s}\right), q^{c s}\right)+w\left(q^{f}, q^{c s}\right) \\
& =\frac{a^{1+x}}{2^{1+x} b} x^{x}\left[\frac{(2+x)(1+2 x-\alpha)+2 \alpha \beta(1+x)}{(2+x)(1+x)^{2}}\right]^{1+x} .
\end{aligned}
$$

It follows from (7) that $u^{d r}\left(q^{c s}\right)$ is increasing with $\alpha$ when $\beta>\frac{2+x}{2(1+x)}$, that is, if this condition holds the gains from the single-period deviation increase as preferences for reciprocity become more important. 


\section{Main Results}

Equations (5), (6) and (7) provide the basic single period payoffs used in determining which is the critical discount factor under which the collusive outcome of the single period Cournot game with selfish firms can be sustained in the infinitely repeated Cournot duopoly with reciprocal firms.

We know that the critical discount factor is given by $\delta_{r}\left(q^{c s}\right)=\frac{u^{d r}-u^{c r}}{u^{d r}-u^{n r}}$. For $\beta \in\left(\frac{2+x}{2+2 x}, 1\right]$ the denominator of this fraction increases since $u^{d r}$ rises whereas $u^{n r}$ falls, however, it is unclear what happens to the numerator since both $u^{d r}$ and $u^{c r}$ rise with $\alpha$. Hence, I expect that for $\beta \in\left(\frac{2+x}{2+2 x}, 1\right)$, the net effect of preferences for reciprocity should be to facilitate collusion for any demand parameters $a, b$ and $x$. By contrast, for $\beta \in\left[0, \frac{2+x}{2+2 x}\right)$ it is unclear what happens to both the numerator and to the denominator of the fraction since $u^{n r}, u^{c r}$, and $u^{d r}$ all fall with $\alpha$.

The general formula for $\delta_{q^{c s}}^{r}(\alpha, \beta, x)$ is cumbersome; however when demand is linear, $x=1$, we have that

$$
\delta_{q^{c s}}^{r}(\alpha, \beta ; 1)=\frac{(3+3 \alpha-4 \alpha \beta)(3-\alpha)^{2}}{3\left(17+3 \alpha-13 \alpha^{2}+\alpha^{3}\right)+4 \alpha \beta\left(7+6 \alpha-\alpha^{2}\right)} .
$$

It follows from (8) that the critical discount factor decreases with an increase in $\beta$ for a fixed $\alpha$. This confirms the intuition that for high levels of perceptions of fair output of the rivals it is easier to sustain collusion. It also follows from (8) that if firms are selfish then $\delta_{q^{c s}}^{s}(1)=\frac{9}{17}$. Let $\hat{\beta}_{1}$ denote the solution to $\delta_{q^{c s}}^{r}(\alpha, \beta ; 1)=\delta_{q^{c s}}^{s}(1)$ with respect to $\beta$. I can now state the following result.

Proposition 1 If $x=1, \alpha<1$ and $\beta>(<) \hat{\beta}_{1}$, then $\delta_{q^{c s}}^{r}(\alpha, \beta ; 1)<(>) \delta_{q^{c s}}^{s}(1)$.

This result shows that if demand is linear and firms' perceptions of the fair output of their rivals are above a threshold level, then the collusive outcome of the single period Cournot duopoly with selfish firms can be sustained at a lower discount factor in the infinitely repeated Cournot duopoly with reciprocal firms than in infinitely repeated Cournot duopoly with selfish firms. However, the opposite happens if firms' perception of the fair output of their rivals are below that same threshold level.

Before discussing the intuition for this result I briefly characterize the threshold level. Solving $\delta_{q^{c s}}^{r}(\alpha, \beta ; 1)=\delta_{q^{c s}}^{s}(1)$ for $\beta$ I find that $\hat{\beta}_{1}=\frac{3}{4} \frac{3+4 \alpha+\alpha^{2}}{27-6 \alpha+\alpha^{2}}$. Since $0<\alpha<1$ we see that $\hat{\beta}_{1} \in(1 / 12,3 / 11)=(.08(3), .(27))$. This implies that if demand is linear then preferences for reciprocity facilitate collusion whenever firms perceive that the fair output of their rivals is greater than or equal to $3 / 11$ of the Nash equilibrium output in the game with selfish firms. In other words, only for quite extreme perceptions of fairness (the fair output of the rival is very low) do preferences for reciprocity make collusion harder.

The intuition behind Proposition 1 is as follows. The punishment imposed after cheating occurs becomes more severe in the game with reciprocal firms 
than in the game with selfish firms for any $\beta \in(0,1)$. This happens because, the one-shot Nash equilibrium of the single period game with reciprocal firms is a negative reciprocity state. This is bad for firms since it reduces monetary profits (by comparison with the monetary profits of selfish firms) and makes firms incur payoff loses from negative reciprocity.

If $\beta \in(3 / 4,1)$ then the payoff from collusion and the gain from the one period deviation are both greater in the game with reciprocal firms than in the game with selfish firms. By contrast, if $\beta \in\left(\hat{\beta}_{1}, 3 / 4\right)$ then the payoff from collusion and the gain from the one period deviation are both smaller in the game with reciprocal firms than in the game with selfish firms. However, the order of magnitude of these two effects is smaller than the order of magnitude of the decrease in the punishment payoff. This implies that collusion becomes easier to sustain in the game with reciprocal firms than in the game with selfish firms for $\beta \in\left(\hat{\beta}_{1}, 1\right)$.

When $\beta \in\left(0, \hat{\beta}_{1}\right)$ firms perceive that the fair output of their rivals is a very low output level. If this happens then the collusive outcome of the game with selfish firms becomes a negative reciprocity state. Additionally, the payoff from the one-period deviation is also smaller in the game with reciprocal firms than in the game with selfish firms. Recall that the punishment strategy, playing the Nash equilibrium of the single period game with reciprocal firms, is also a negative reciprocity state. In this case, the order of magnitude of the reduction in the payoff of the collusive outcome is larger than the reduction in either the deviation or the punishment payoff. Thus, it is harder to sustain collusion with reciprocal firms than we selfish firms when $\beta \in\left(0, \hat{\beta}_{1}\right)$.

Is Proposition 1 driven by the specific functional form of demand? To address this question I now consider a situation where demand is nonlinear. When $x=2$ the demand function is convex and the critical discount factor above reciprocal firms are able to sustain the collusive outcome of the game with selfish firms is given by

$$
\delta_{q^{c s}}^{r}(\alpha, \beta ; 2)=\frac{\left[(10-2 \alpha+3 \alpha \beta)^{3}-432(2-2 \alpha+3 \alpha \beta)\right](2-\alpha)^{3}}{(10-2 \alpha+3 \alpha \beta)^{3}(2-\alpha)^{3}-729(2-2 \alpha+\alpha \beta)^{3}} .
$$

It follows from (9) that if firms are selfish then $\delta_{q^{c s}}^{s}(2)=\frac{136}{271}$. Let $\hat{\beta}_{2}$ denote the solution to $\delta_{q^{c s}}^{r}(\alpha, \beta ; 2)=\delta_{q^{c s}}^{s}(2)$ with respect to $\beta$.

Proposition 2 If $x=2, \alpha<\frac{1}{2}$ and $\beta>(<) \hat{\beta}_{2}$, then $\delta_{q^{c s}}^{r}(\alpha, \beta ; 2)<(>) \delta_{q^{c s}}^{s}(2)$.

This result shows that even if demand is nonlinear the main findings of Proposition 1 are still valid, that is, above a certain threshold level of perceptions of fairness, the collusive outcome of the single period Cournot duopoly with selfish firms can be sustained at a lower discount factor in the infinitely repeated Cournot duopoly with reciprocal firms than in the infinitely repeated Cournot duopoly with selfish firms.

Solving $\delta_{q^{c s}}^{r}(\alpha, \beta ; 2)=\delta_{q^{c s}}^{s}(2)$ we obtain a complicated expression for $\hat{\beta}_{2}$ as a function of $\alpha$. Evaluating $\hat{\beta}_{2}(\alpha)$ at the extreme points, that is $\alpha=0$ and 
$\alpha=.5$, I find that $\hat{\beta}_{2} \in\left(\frac{41}{750}, \frac{168}{1223}\right)=(.054667, .13723) .{ }^{9}$ This shows that, just like in the linear demand case, the threshold level $\hat{\beta}_{2}$ is at a low value, that is, for $x=2$ collusion is easier to sustain in the infinitely repeated Cournot duopoly with reciprocal firms than in the infinitely repeated Cournot duopoly with selfish firms for a plausible range of firms' perceptions of the fair output of their rivals.

\section{$5 \quad$ Additional Findings}

There is another effect of reciprocity between firms that may be adverse for consumers. The best collusive outcome for reciprocal firms is worse for consumers than the best collusive outcome for selfish firms. To show this I will compute the best collusive outcome when firms have preferences for reciprocity and compare it to the collusive outcome of the game with selfish firms.

The best collusive outcome of the game with reciprocal firms is the solution to the following problem

$$
\max _{q_{1}, q_{2}} u_{1}\left(q_{1}, q_{2}\right)+u_{2}\left(q_{1}, q_{2}\right)
$$

The first-order conditions to this problem are

$$
(a-b Q)^{x-1}\left[(1-\alpha)\left(a-b\left(q_{i}+q_{j}\right)\right)-b x\left((1-\alpha)\left(q_{i}+q_{j}\right)+\frac{2 \alpha \beta a}{b(2+x)}\right)\right]=0,
$$

$i \neq j=1,2$. The symmetry assumptions imply that the best collusive quantity of the game with reciprocal firms is given by

$$
q^{c r}=\frac{a}{2 b} \frac{2+x-\alpha(2+x+2 \beta x)}{(2+x)(1+x)(1-\alpha)} .
$$

I use this expression to prove the next result.

Proposition 3 If $\alpha>0$ and $\beta \in(0,1]$, then $q^{c r}<q^{c s}$.

Proposition 3 tells us that the best collusive outcome of the dynamic Cournot duopoly with reciprocal firms is worse for consumers than the best collusive outcome of the dynamic Cournot duopoly with selfish firms. This result follows directly from (10). We can see from (10) that the collusive quantity of the game with reciprocal firms is decreasing with $\beta$, that is, the greater is a firm's perception of the fair output level of its rival the less that firm will produce in the best collusive outcome of the game with reciprocal firms. ${ }^{10}$

\footnotetext{
${ }^{9}$ The value $\hat{\beta}_{2}(.5)=\frac{168}{1223}$ is obtained by substituting $\alpha=.5$ into the expression $\hat{\beta}_{2}(\alpha)$. The value $\hat{\beta}_{2}(0)=\frac{41}{750}$ is obtained by application of L'Hopital's rule to $\lim _{\alpha \rightarrow 0} \hat{\beta}_{2}(\alpha)$.

${ }^{10}$ It also follows from (10) that the best collusive outcome of the game with reciprocal firms is equal to the best collusive outcome of the game with selfish firms when $\beta=0$.
} 
However, sustaining the best collusive outcome of in the dynamic Cournot duopoly with reciprocal firms requires a higher discount factor than sustaining the best collusive outcome of the dynamic Cournot duopoly with selfish firms. This result is stated in Proposition 4 for the cases $x=1$ and $x=2$.

\section{Proposition 4}

(i) If $x=1$ and $\alpha<1$ then $\delta_{q^{c r}}^{r}(\alpha, \beta ; 1)>\delta_{q^{c s}}^{s}(1)$.

(ii) If $x=2$ and $\alpha<.5$ then $\delta_{q^{c r}}^{r}(\alpha, \beta ; 2)>\delta_{q^{c s}}^{s}(2)$.

This result follows because the incentive a reciprocal firm has to deviate from the best collusive outcome of the game with reciprocal firms is greater than the incentive a selfish firm has to deviate from the best collusive outcome of the game with selfish firms.

The model also predicts that firms' monetary profits in the best collusive outcome of the game with reciprocal firms are lower than those in the best collusive outcome of the game with selfish firms. This result is not surprising since by definition reciprocal firms do not maximize monetary profits, they maximize a combination of monetary profits and payoffs from reciprocity.

\section{Price Competition}

This section studies the impact of preferences for reciprocity on collusion in the infinitely repeated Bertrand game. To do that I consider the case of two firms, 1 and 2. The payoff of a reciprocal firm is assumed to be

$$
u_{i}\left(p_{i}, p_{j}\right)=\pi_{i}\left(p_{i}, p_{j}\right)+w_{i}\left(p_{j}, p^{f}\right) \pi_{j}\left(p_{i}, p_{j}\right), \quad i \neq j=1,2,
$$

where

$$
w_{i}\left(p_{j}, p^{f}\right)\left\{\begin{array}{l}
>0 \text { if } p_{j}>p^{f} \\
=0 \text { if } p_{j}=p^{f} \\
<0 \text { otherwise }
\end{array}\right.
$$

that is, firm $i$ places a positive weight on its rival's monetary profits when the rival sets a price below than the fair price, $p^{f}$, firm $i$ places no weight on its rival's monetary profits when the rival sets price equal to $p^{f}$, and firm $i$ places a negative weight on its rival's monetary profit when the rival sets a price above $p^{f}$. I assume that the fair price is equal to or above marginal cost, $c$, and equal to or lower than the monopoly price, $p^{m}$, that is $p^{f} \in\left[c, p^{m}\right]$, where $p^{m}=\max _{p}(p-c) D(p)$, where $D(p)$ is demand.

It is a well know result that the critical discount factor at which selfish firms can sustain collusion at the monopoly price is equal to $1 / 2$. In effect, a selfish firm $i$ prefers to not deviate from the monopoly price if the discounted payoff of cooperation forever is larger than the one period gain of deviation, that is

$$
\frac{1}{1-\delta} \frac{1}{2}\left[\left(p^{m}-c\right) D\left(p^{m}\right)\right] \geq\left(p^{m}-c\right) D\left(p^{m}\right),
$$


or

$$
\delta_{p^{m}}^{s} \geq \frac{1}{2}
$$

If firms have preferences for reciprocity the no deviation condition becomes

$$
\frac{1}{1-\delta}\left[\frac{1}{2}+w\left(p^{m}, p^{f}\right)\right]\left(p^{m}-c\right) D\left(p^{m}\right) \geq\left(p^{m}-c\right) D\left(p^{m}\right) .
$$

Since $w\left(p^{m}, p^{f}\right) \geq 0$ it follows that

$$
\delta_{p^{m}}^{r} \geq \frac{1}{2}-w\left(p^{m}, p^{f}\right) \geq \delta_{p^{m}}^{s}
$$

Thus, preferences for reciprocity always facilitate collusion in the infinitely repeated Bertrand duopoly.

\section{Conclusion}

This paper extends the standard models of industrial economics used to study collusion to include preferences for reciprocity. A selfish firm only cares about monetary profits. By contrast, a reciprocal firm cares about monetary profits but also about the intentions of its rivals. The paper finds that, for plausible perceptions of fairness, firms' preferences for reciprocity facilitate collusion in the infinitely repeated Cournot and Bertrand market games. 


\section{References}

Abdulkadiroğlu, Atila and Kyle Bagwell (2005). "Trust, Reciprocity and Favors in Cooperative Relationships," Working Paper, Department of Economics, Colombia University.

Bolton, G. and A. Ockenfels (2000). "ERC: A Theory of Equity, Reciprocity, and Competition," American Economic Review, 90(1): pp. 166-193.

Feuerstein, Switgard (2005). "Collusion in Industrial Economics-A Survey," Journal of Industry, Competition and Trade, 5:3/4, 163-198.

Malueg, David (1992). "Collusive Behavior and Partial Ownership of Rivals," International Journal of Industrial Organization, Vol. 10, 1, 27-34.

Rabin, Matthew (1993). "Incorporating Fairness into Game Theory and Economics," American Economic Review, 83, 1281-1302.

Santos-Pinto, Luís (2006). "Reciprocity, Inequity Aversion, and Oligopolistic Competition," Working Paper Universidade Nova de Lisboa.

Segal, Uzi, and Joel Sobel (1999). "Tit for Tat: Foundations of Preferences for Reciprocity in Strategic Settings," Working Paper, UCSD.

Sobel, Joel (2005). "Interdependent Preferences and Reciprocity," Journal of Economic Literature, Vol. XLIII, 392-436.

Vives, Xavier (2001). Oligopoly Pricing: Old Ideas and New Tools, The MIT Press. 


\section{Appendix}

Proof. of Proposition 1: Setting (8) equal to $9 / 17$ and solving for $\beta$ we obtain $\hat{\beta}_{1}=\frac{3}{4} \frac{3+4 \alpha+\alpha^{2}}{27-6 \alpha+\alpha^{2}}$. I need to show that $\beta \in\left(\hat{\beta}_{1}, 1\right]$ implies $\delta_{q^{c s}}^{r}(\alpha, \beta ; 1)<9 / 17$. To do that I compare $\delta_{q^{c s}}^{r}(\alpha, \beta ; 1)$ to $9 / 17$. Rearranging (8) I have that

$$
\delta_{q^{c s}}^{r}(\alpha, \beta ; 1)=\left(1+\frac{8\left(1+8 \alpha \beta-\alpha^{2}\right)}{(1+\alpha-4 \alpha \beta)(3-\alpha)^{2}}\right)^{-1} .
$$

I also have that

$$
\delta_{q^{c s}}^{r}(1)=\frac{9}{17}=\left(1+\frac{8}{9}\right)^{-1} .
$$

It follows that $\hat{\beta}_{1}=\frac{1}{4} \frac{3+4 \alpha+\alpha^{2}}{27-6 \alpha+\alpha^{2}}<\beta$ is equivalent to $\frac{8}{9}<\frac{8\left(1+8 \alpha \beta-\alpha^{2}\right)}{(1+\alpha-4 \alpha \beta)(3-\alpha)^{2}}$. This shows that if $x=1$ and $\beta \in\left(\hat{\beta}_{1}, 1\right]$ then $\delta_{q^{c s}}^{r}(\alpha, \beta ; 1)<9 / 17=\delta_{q^{c s}}^{s}(1)$. Q.E.D.

Proof. of Proposition 2: First I will show that there exists a $\hat{\beta}_{2} \in(0,1)$ such that $\delta_{q^{c}}^{r}(\alpha, \beta, 2)=\delta_{q^{c}}^{s}(2)$. The critical discount factor at $\beta=0$ is given by $\delta_{q^{c}}^{r}(\alpha ; 0,2)=\frac{(17-\alpha)(2-\alpha)^{3}}{\alpha^{4}-23 \alpha^{3}+222 \alpha^{2}-455 \alpha+271}$. We have that

$$
\delta_{q^{c}}^{r}(\alpha ; 0,2)-\frac{136}{271}=\frac{27 \alpha}{271} \frac{164+26 \alpha-115 \alpha^{2}+5 \alpha^{3}}{271-455 \alpha+222 \alpha^{2}-23 \alpha^{3}+\alpha^{4}}>0,
$$

since $\alpha \in(0, .5)$. The critical discount factor at $\beta=1$ is given by $\delta_{q^{c}}^{r}(\alpha ; 1,2)=$ $\frac{136-132 \alpha+30 \alpha^{2}+\alpha^{3}}{271+300 \alpha+30 \alpha^{2}+\alpha^{3}}$. We have that

$$
\delta_{q^{c}}^{r}(\alpha ; 1,2)-\frac{136}{271}=\frac{27 \alpha}{271} \frac{-2836+150 \alpha+5 \alpha^{2}}{271+300 \alpha+30 \alpha^{2}+\alpha^{3}}<0,
$$

since $\alpha \in(0, .5)$. It follows from (9) that the critical discount factor is a continuous function of $\alpha$ and $\beta$ for $\alpha \in(0, .5)$ and $\beta \in[0,1]$ and is decreasing with $\beta$ for any $\alpha$. Thus, (12) and (13) imply that there exists a $\hat{\beta}_{2} \in(0,1)$ such that $\delta_{q^{c}}^{r}(\alpha, \beta, 2)=\delta_{q^{c}}^{s}(2)$. But, then $\delta_{q^{c}}^{r}(\alpha, \beta, 2)<\delta_{q^{c}}^{s}(2)$ for $\beta \in\left(\hat{\beta}_{2}, 1\right]$ and $\delta_{q^{c}}^{r}(\alpha, \beta, 2)>\delta_{q^{c}}^{s}(2)$ for $\beta \in\left[0, \hat{\beta}_{2}\right)$.

Q.E.D.

Proof. of Proposition 3: The quantity produced in the best collusive outcome of the game with selfish firms is $q^{c s}=\frac{1}{1+x} \frac{a}{2 b}$. If firms have preferences for reciprocity the quantity produced in the best collusive outcome, $q^{c r}$, is given by (10). It follows that $\alpha>0$ and $\beta \in(0,1]$ imply that $q^{c r}=\frac{2+x-\alpha(2+x+2 \beta x)}{(2+x)(1+x)(1-\alpha)} \frac{a}{2 b}<$ $\frac{1}{1+x} \frac{a}{2 b}=q^{c s}$.

Q.E.D. 
Proof. of Proposition 4: The best collusive outcome in the game with reciprocal firms is given by (10) and its payoff is

$$
u^{c r}\left(q^{c r}\right)=\frac{(-2 \alpha \beta+2 \alpha+\alpha x-2-x)^{1+x}}{\left(-2+2 \alpha-3 x+3 \alpha x-x^{2}+x^{2} \alpha\right)^{x}} \frac{a^{1+x} x^{x}}{2 b(1+x)(2+x)} .
$$

The optimal output of firm $i$ if it deviates from the best collusive outcome of the game with reciprocal firms is given by

$$
\begin{aligned}
B R^{r}\left(q^{c r}\right) & =\frac{2+x-\alpha \beta x}{(2+x)(1+x)} \frac{a}{b}-\frac{1-\alpha x}{1+x} \frac{2+x-\alpha(2+x+2 \beta x)}{(2+x)(1+x)(1-\alpha)} \frac{a}{2 b} \\
& =\frac{a\left[2-2 \alpha+x\left(5-3 \alpha+2 x-x \alpha+2 \alpha^{2} \beta-2 \alpha \beta x-2 \alpha^{2}-\alpha^{2} x\right)\right]}{2 b(1+x)^{2}(2+x)(1-\alpha)}
\end{aligned}
$$

The payoff from the deviation is equal to

$$
u^{d r}\left(q^{c r}\right)=\frac{x^{x}[2-2 \alpha(2-\alpha-\beta+\alpha \beta)+x(5+2 x-\alpha(6+2 x-\alpha-4 \beta))]^{1+x}}{a^{-(1+x)} 2^{1+x} b(1+x)^{2+2 x}(2+x)^{1+x}(1-\alpha)^{1+x}}
$$

The critical discount factor above which it is possible to sustain the best collusive outcome of the game with reciprocal firms is given by

$$
\delta_{q^{c r}}^{r}(\alpha, \beta, x)=\frac{u^{d r}\left(q^{c r}\right)-u^{c r}\left(q^{c r}\right)}{u^{d r}\left(q^{c r}\right)-u^{n r}\left(q^{c r}\right)} .
$$

For $x=1$ we obtain $\delta_{q^{c r}}^{r}(\alpha, \beta ; 1)=\frac{(3-\alpha)^{2}}{17-14 \alpha+\alpha^{2}}>\frac{9}{17}$ for any $\alpha \in(0,1)$. For $x=2$ we obtain $\delta_{q^{c r}}^{r}(\alpha, \beta ; 2)=\frac{(2-\alpha)^{3}(17-\alpha)}{\alpha^{4}-23 \alpha^{3}+222 \alpha^{2}-455 \alpha+271}>\frac{136}{271}$ for any $\alpha \in$ $(0, .5)$.

Q.E.D. 